NBER WORKING PAPER SERIES

OPTIMAL BAILOUTS AND THE DOOM LOOP WITH A FINANCIAL NETWORK

\author{
Agostino Capponi \\ Felix C. Corell \\ Joseph E. Stiglitz \\ Working Paper 27074 \\ http://www.nber.org/papers/w27074 \\ NATIONAL BUREAU OF ECONOMIC RESEARCH \\ 1050 Massachusetts Avenue \\ Cambridge, MA 02138 \\ May 2020, Revised January 2022
}

We would like to thank the editor, three anonymous referees, Árpád Ábrahám, Viral Acharya, Thorsten Beck, Edouard Challe, Nicola Fuchs-Schündeln, Paul Glasserman, Piero Gottardi, Philipp Grübener, Philipp Kircher, Anton Korinek, Steve Kou, Ramon Marimon, Lukas Nord, Giorgia Piacentino, Vincenzo Quadrini, Rafael Repullo, Stefan Schmitz, our discussants Flora Lutz, Anjan Thakor, and Dimitri Vayanos, conference participants at the 5th Annual Conference on Network Science in Economics, the EEA Virtual Congress 2020, the 7th Sovereign Bond Markets Conference 2020 (Bank of England), the 9th Workshop on Banks and Financial Markets (Vienna), the 2021 SED Annual Meeting, the 20th Annual FDIC/JFSR Bank Research Conference, and seminar participants at NYU and EUI for their helpful comments. The views expressed herein are those of the authors and do not necessarily reflect the views of the National Bureau of Economic Research.

NBER working papers are circulated for discussion and comment purposes. They have not been peer-reviewed or been subject to the review by the NBER Board of Directors that accompanies official NBER publications.

(C) 2020 by Agostino Capponi, Felix C. Corell, and Joseph E. Stiglitz. All rights reserved. Short sections of text, not to exceed two paragraphs, may be quoted without explicit permission provided that full credit, including $\odot$ notice, is given to the source. 
Optimal Bailouts and the Doom Loop with a Financial Network Agostino Capponi, Felix C. Corell, and Joseph E. Stiglitz

NBER Working Paper No. 27074

May 2020, Revised January 2022

JEL No. G01,G21,G28,H63,H81

\begin{abstract}
$\underline{\text { ABSTRACT }}$
Banks usually hold large amounts of domestic debt which makes them vulnerable to their own sovereign's default risk. At the same time, governments often resort to costly bailouts when their banking sector is in trouble. We investigate how the network structure and the distribution of ownership of sovereign debt within the banking sector jointly affect the optimal bailout policy under this "doom loop". We argue that rescuing banks with high domestic sovereign exposure is optimal if these banks are sufficiently central, even though that requires larger bailout expenditures than rescuing otherwise identical low-exposure banks. Our model illustrates how the "doom loop" exacerbates the "too interconnected to fail" problem.
\end{abstract}

Agostino Capponi

Mudd Hall 535-G

Columbia University

500 W 120th St.

New York, NY 10027

ac3827@columbia.edu
Joseph E. Stiglitz

Uris Hall, Columbia University

3022 Broadway, Room 212

New York, NY 10027

and NBER

jes322@columbia.edu

Felix C. Corell

Department of Economics

European University Institute

felix.corell@eui.eu 


\title{
Optimal Bailouts and the Doom Loop with a Financial Network ${ }^{\star}$
}

\author{
Agostino Capponi ${ }^{\mathrm{a}, *}$, Felix Corell ${ }^{\mathrm{b}}$, Joseph E. Stiglitz ${ }^{\mathrm{a}}$ \\ ${ }^{a}$ Columbia University, 3022 Broadway, New York, NY 10027 \\ ${ }^{b}$ European University Institute, Via delle Fontanelle 18, 50014 San Domenico di Fiesole
}

\begin{abstract}
Banks usually hold large amounts of domestic debt which makes them vulnerable to their own sovereign's default risk. At the same time, governments often resort to costly bailouts when their banking sector is in trouble. We investigate how the network structure and the distribution of ownership of sovereign debt within the banking sector jointly affect the optimal bailout policy under this "doom loop". We argue that rescuing banks with high domestic sovereign exposure is optimal if these banks are sufficiently central, even though that requires larger bailout expenditures than rescuing otherwise identical low-exposure banks. Our model illustrates how the "doom loop" exacerbates the "too interconnected to fail" problem.
\end{abstract}

Keywords: Financial networks, home bias, sovereign debt, bailouts, doom loop

\section{Introduction}

Throughout modern economic history, almost every major crisis has added its own signature terms to the dictionary of economic thought. For the European sovereign debt crisis that followed the Great Recession in 2008/09, one of the front-running candidates is certainly the so-called bank-sovereign "doom loop" - a term that has made its way into the vocabulary of policymakers, journalists, and researchers alike. The nexus between sovereigns and banks was

${ }^{\star}$ We would like to thank the editor, three anonymous referees, Árpád Ábrahám, Viral Acharya, Thorsten Beck, Edouard Challe, Nicola Fuchs-Schündeln, Paul Glasserman, Piero Gottardi, Philipp Grübener, Philipp Kircher, Anton Korinek, Steve Kou, Ramon Marimon, Lukas Nord, Giorgia Piacentino, Vincenzo Quadrini, Rafael Repullo, Stefan Schmitz, our discussants Flora Lutz, Anjan Thakor, and Dimitri Vayanos, conference participants at the $5^{\text {th }}$ Annual Conference on Network Science in Economics, the EEA Virtual Congress 2020, the $7^{\text {th }}$ Sovereign Bond Markets Conference 2020 (Bank of England), the $9^{\text {th }}$ Workshop on Banks and Financial Markets (Vienna), the 2021 SED Annual Meeting, the $20^{\text {th }}$ Annual FDIC/JFSR Bank Research Conference, and seminar participants at NYU and EUI for their helpful comments.

${ }^{*}$ Corresponding author

Email address: ac3827@columbia.edu (Agostino Capponi) 
identified as a major culprit responsible for the amplification of adverse shocks during the crisis.

The doom loop can be described as follows: Banks usually hold large amounts of domestic public debt which makes them vulnerable to sovereign default risk. For instance, as of March

\footnotetext{
${ }^{1}$ Note for example that Italian banks currently hold around $10 \%$ of their assets in domestic sovereign debt (Figure 1).

${ }^{2}$ For example, on 28 April 2020 the rating agency Fitch lowered Italy's sovereign rating on the grounds of the expected repercussions from the Covid-19 pandemic; just two weeks later, on 12 May 2020, a downgrade of four of the biggest Italian banks (UniCredit, Intesa Sanpaolo, Mediobanca, UBI) followed suit. However, thanks in part to the ECB's accommodative monetary policy, Italian sovereign spreads have not persistently increased.
} 
structure of the interbank network jointly affect the government's optimal bailout decision in the presence of the doom loop. In doing so, we combine two strands of literature that have so far ¿volved separately, namely the doom loop literature (e.g. Acharya et al. (2014), Brunnermeier et al. (2016), Cooper and Nikolov (2018), Farhi and Tirole (2018)) and the literature about contagion in financial networks (Allen and Gale (2000), Battiston et al. (2012a) b), Acemoglu et al. (2015), Elliott et al. (2014), Cabrales et al. (2017)). More precisely, we consider an exogenous network of (unsecured) interbank liabilities after an adverse shock has rendered a set of banks insolvent. Each bank holds an exogenous amount of its own government's bonds.

40 Without any government intervention, there may be a default cascade in the banking system that causes large welfare losses due to bankruptcy deadweight costs (depositors are protected by a well-functioning deposit insurance scheme). The government can, however, reduce these losses by bailing out some or all of the failing banks. To do so, the government must borrow the required funds in the sovereign debt market which pushes down bond prices and thus puts further pressure on banks' balance sheets. A rational government internalizes this "secondround" effect, so bailouts are, by definition, large enough to cover the total shortfall of the banks to be rescued. The government trades off the welfare losses of a default cascade against those associated with a higher sovereign default probability, as bank liabilities effectively move onto the government's balance sheet.

Our model is related to existing models of intervention in networks, but there is a fundamental difference: Without the doom loop, bailouts of different banks would be complementary in the sense that bailing out one bank weakly decreases the pecuniary cost of bailing out other banks (because their shortfall weakly decreases). In our model, however, this relationship can break down if other banks possess large holdings of sovereign debt. In such a case, bailing out one bank might make bailouts of other banks even more expensive. In other words, there can be both "crowding out" and "crowding in" of further bailouts.

Existing literature distinguishes two types of financial contagion, namely direct contagion due to counterparty default (see Glasserman and Young (2016) for a survey) and indirect contagion through common asset exposures, fire sales, or deposit withdrawals (Shleifer and Vishny (2011); Greenwood et al. (2015)). There is an ongoing debate about which type of contagion is empirically more relevant, and many studies (including Upper (2011), Brunnermeier et al. 
(2009), and Glasserman and Young (2015)) suggest that it is the latter. The main argument is that with empirically observed interbank debt levels, shocks would have to be unrealistically large in order to explain past crisis episodes with direct contagion only.

We argue that direct contagion is an economically significant channel for two main reasons: First, as observed in Glasserman and Young (2015), bankruptcy deadweight losses significantly increase the costs resulting from direct contractual exposures. In this regard, during a hearing before the House Committee on Oversight and Government Reform in January 2010, former US Treasury Secretary Timothy Geithner cited fear of the fallout from legal disputes and protracted negotiations with counterparties in case of bankruptcy as one of the main justifications for AIG's bailout in 2008. Second, the usual drivers of indirect contagion (e.g., deposit withdrawals or fire sales) are themselves a function of underlying counterparty risk and hence direct contagion. For instance, depositors may run on banks partly because they expect their bank to suffer from the default of a counterparty in the network. Even though losses due to fire-sale contagion and deposit withdrawals may be larger, one would need a clean empirical identification strategy to disentangle the two channels. ${ }^{3}$

In our model, direct and indirect contagion interact in a nontrivial fashion: The government, by preventing direct contagion (default cascades), can trigger indirect contagion of otherwise healthy banks that hold domestic sovereign bonds (common asset holdings). However, our paper abstracts from more general macroeconomic effects, such as an increase in unemployment, a reduction in output, or a contraction of government revenues, that might result from bank failures. These effects, which can be thought of as macroeconomic externalities, were, of course, central to some of the earlier doom loop literature (see, e.g., Brunnermeier et al. (2016)).

Our first set of results applies to the special case of complete bailouts where the government can only bail out all banks or none. We show (not surprisingly) that the doom loop makes complete bailouts socially more costly if a larger amount of sovereign debt is held by domestic banks. Moreover, for a given aggregate amount of sovereign debt held by the banking sector, it is socially preferable that it be held by relatively well-capitalized banks. The intuition for

\footnotetext{
${ }^{3}$ To the best of our knowledge, no natural experiment exists that allows to measure the effect of systemic risk from fire-sales and deposit withdrawals independently of the counterparty contagion channel stemming from contractual relations.
} 
these results is straightforward: Financing a bailout imposes a cost on banks that are exposed losses will be. If, in contrast, public debt is largely held by weakly capitalized banks, the doom loop hits them with a stronger force and the required bailout may become very large.

Our second set of results generalizes the bailout decision by allowing the government to bail out any subset of banks (partial bailouts). The government chooses the set of surviving

\section{Related Literature}

As noted in the introduction, our paper leverages insights from two strands of literature: the financial contagion literature and the large "doom loop" literature that has emerged in recent 
years in response to the European sovereign debt crisis.

The financial contagion literature began well before the 2008 crisis, with the seminal articles

et al. (2016). The first is the "real economy loop" where sovereign stress reduces economic activity and lowers tax revenues, thereby increasing the stress even more. A standard channel through with this occurs is credit: sovereign stress reduces the value of public debt on banks'

4 Altavilla et al. (2017) and Popov and Van Horen (2015) find that during the European sovereign debt crisis banks with higher exposure to stressed sovereigns cut their lending to the domestic real economy significantly 
that constitutes the focus of this paper.

Acharya et al. (2014) provide empirical evidence for both "directions" of the loop. They show that (a) bailouts triggered the rise of sovereign credit risk in 2008 and (b) changes in sovereign CDS rates in turn explain changes in bank CDS rates. The perceived stabilization of the banking sector through a bailout can thus turn out to be a "Pyrrhic victory". In more recent work, Hur et al. (2021) confirm the finding that the "diabolic loop" caused by bank bailouts can be too costly to justify them.

Acharya et al. (2014) and Farhi and Tirole (2018) develop theoretical models of the "deadly embrace" that are related to ours, but do not consider interbank linkages and therefore the implications of network structure. Cooper and Nikolov (2018) study the strategic interaction between banks and the government. They show that if the government cannot commit to a credible no-bailout policy, banks in a subgame perfect Nash equilibrium anticipate a bailout and choose insufficient equity buffers. While in our model banks are inactive agents with exogenous balance sheets, our analysis of partial bailouts suggests that in a dynamic setting banks could influence the odds of being bailed out through their sovereign debt exposure.

Finally, our paper indirectly relates to a strand of literature that empirically tests different hypotheses of why euro area banks exhibited increasing sovereign debt "home bias" during and after the crisis. Altavilla et al. (2017) and Crosignani (2021) all find that the observed increase in domestic sovereign debt holdings during the crisis was stronger for poorly capitalized banks. This finding is worrisome if viewed in the context of our results on complete bailouts. As we show in the paper, bailouts are socially more costly if domestic sovereign debt is largely held by fragile banks.

\section{Model}

Our model has three periods $t=0,1,2$ and features a set of banks $N=\{1, \ldots, n\}$ and a benevolent government that maximizes welfare. In the initial period $t=0$, an exogenous, unanticipated shock (e.g. a pandemic or the burst of a housing bubble) hits a subset of the banks and lowers the value of their assets below that of their liabilities. Without a public

more than banks with low exposure. 
bailout in $t=1$ a cascade of bank defaults with associated bankruptcy deadweight costs may unfold. However, the government can decide to issue new debt in $t=1$ and transfer funds to

Some banks face a shortfall of $\chi_{0} \equiv\left(L+d-c-q_{0} b-(\Pi L)\right)^{+}$, e.g., as a consequence of a natural disaster or a pandemic. Since all bank liabilities are due at $t=1$ the insolvent banks will have to default on their obligations if they are not bailed out. We denote the set of these fundamentally defaulting banks by $\mathcal{F} \equiv\left\{i \mid \chi_{0}^{i}>0\right\}$. 
Since banks are interlinked through debt contracts, the fundamental default of one or more banks can lead to further defaults elsewhere in the system. If bank $j$ defaults, it has to liquidate all its (interbank and other) assets and repay its creditors according to their seniority. Deposits $d^{j}$ have seniority over interbank liabilities $L^{j}$, and thanks to deposit insurance, depositors are always reimbursed for their losses. Among interbank creditors, the total repayment $p^{j}<L^{j}$ is then distributed pro rata, i.e., the creditor bank $i$ of a defaulting bank $j$ is repaid according to its share $\pi^{i j}$ in bank $j$ 's interbank liabilities.

As in Glasserman and Young (2015) we assume that whenever a bank defaults, some of its assets are destroyed ("deadweight loss"). More precisely, the default of bank $j$ comes at a

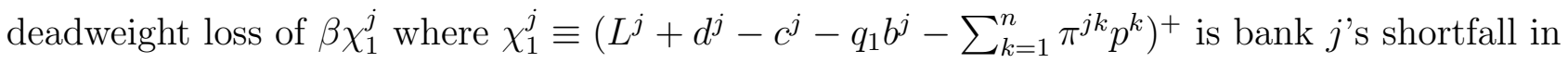
period $t=1$ and $\beta>0$ a scaling parameter ${ }^{5}$ The deadweight loss is increasing in the bank's shortfall and can be interpreted as legal costs or losses due to delays or an inefficient allocation of resources during the bankruptcy procedure.

We further assume that interbank liabilities are cleared simultaneously at $t=1$, as in Eisenberg and Noe (2001) : 6 This leads to the following definition:

Definition 1. A clearing payment vector $p=\left(p^{1}, \ldots, p^{n}\right)$ for a financial system $(L, \Pi, c, d, b)$ is a fixed point of

$$
p^{i}= \begin{cases}L^{i} & \text { if } \quad c^{i}+q_{1} b^{i}+\sum_{j=1}^{n} \pi^{i j} p^{j} \geq L^{i}+d^{i} \\ \left(c^{i}+q_{1} b^{i}+\sum_{j=1}^{n} \pi^{i j} p^{j}-d^{i}-\beta \chi_{1}^{i}\right)^{+} & \text {otherwise }\end{cases}
$$

The existence of multiple, Pareto ranked clearing payment vectors in this setting follows directly from Proposition 3 in Glasserman and Young (2015). Following the standard convention in this literature, we focus on the unique Pareto dominant clearing payment $\bar{p}$, i.e., the "best case" scenario with the highest repayments 7 We define the set of defaulting banks under a

\footnotetext{
${ }^{5}$ According to our definition, the deadweight loss caused by a defaulting bank is bounded from above by the total value of its assets. This feature reflects the fact that large banks can generally cause more damage than small banks. To keep the model tractable, we focus on settings where this upper bound is not binding, i.e., $\chi_{0}^{i}$ and $\beta$ are small enough to ensure that no bank's assets are completely wiped out in bankruptcy.

${ }^{6}$ Uncertainty about the order of defaults and delays in repayments would add to the severity of default cascades. In the model, we capture these frictions in reduced form as deadweight losses.

${ }^{7}$ In a recent article, Jackson and Pernoud (2020) study the optimal bailout transfers needed to avoid self-
} 
clearing payment vector $\bar{p}$ as $\mathcal{D}(\bar{p}) \equiv\left\{i \mid \bar{p}^{i}<L^{i}\right\}$. Clearly, $\mathcal{D}(\bar{p}) \supseteq \mathcal{F}$ because $\mathcal{D}(\bar{p})$ can also

\subsection{Government}

In our model, the government faces a tradeoff in minimizing expected welfare losses at $t=1$. On the one hand, it wants to avoid bank defaults and the associated deadweight losses. On the other hand, rescuing banks with debt-financed bailouts is also costly because liabilities are effectively moved from private to the public balance sheet, resulting in higher sovereign spreads and a higher probability of a costly sovereign default.

We assume that all sovereign debt matures in the final period $t=2$ and is held either by domestic banks or risk-neutral investors (external to the network), so the (exogenous) total initial stock of sovereign debt is given by $B_{0}=\sum_{i=1}^{n} b^{i}+b_{0}^{I n v}$, where $b_{0}^{I n v}$ denotes the holdings of risk-neutral non-bank investors.

At $t=1$ the government can choose to prevent a default cascade by issuing additional debt to finance bank bailout transfers..$^{8}$ More precisely, the government chooses the set $\mathcal{S} \subseteq N$ of surviving banks (and equivalently its complement $\mathcal{S}^{c}=N \backslash \mathcal{S}$ ) to minimize the expected welfare losses arising from bank bankruptcies and (expected) sovereign default, to be defined further below. By choosing the set of surviving banks, the government effectively also chooses (a) the unique clearing payment vector $\bar{p}(\mathcal{S}): \bar{p}^{i}=L^{i} \forall i \in \mathcal{S}$, and (b) the unique set of bailout transfers that is just sufficient to cover the shortfalls of all banks in $\mathcal{S}$ :

$$
t^{i}\left(\mathcal{S}, q_{1}\right)=\left(L^{i}+d^{i}-c^{i}-q_{1} b^{i}-(\Pi \bar{p}(\mathcal{S}))^{i}\right)^{+} \quad \forall i \in \mathcal{S}
$$

To raise a given amount of total bailouts $T\left(\mathcal{S}, q_{1}\right)=\sum_{i \in \mathcal{S}} t^{i}\left(\mathcal{S}, q_{1}\right)$, the government needs to

fulfilling cycles of defaults, i.e., how to achieve the Pareto dominant clearing payment vector.

${ }^{8}$ Our notion of bailouts, i.e., direct transfers (equivalent to a capital injection in our model), is not the only conceivable way to prevent bank failures. For example, debt renegotiation, forced mergers with healthy banks, or voluntary, incentive-compatible bail-ins of surviving creditor banks as in Bernard et al. (2022) are also appropriate resolution policies. A fourth alternative would be a tax-financed bailout (instead of debt-financed), which would affect the price of sovereign debt as well through a loss in GDP. The optimal bailout design is outside the scope of this paper. 
increase the outstanding debt level to $B_{1}>B_{0}$, so to satisfy the following budget constraint:

$$
q_{1}\left(B_{1}-B_{0}\right)=T\left(\mathcal{S}, q_{1}\right)
$$

In the final period $t=2$ the government raises taxes to repay its obligations $B_{1}$. We assume that the government's tax capacity (i.e., the maximum revenue it can raise) $\tilde{\tau}$ is a random variable that follows a continuous and strictly monotonic cumulative distribution function (CDF) $F(\tau) 9^{9}$ If $\tau \geq B_{1}$, the government raises exactly enough to repay all debt in full. If, however, $\tau<B_{1}$, we assume the government collects nothing and fully defaults on all its obligations, i.e. bondholders do not receive any repayment at all ${ }^{10}$ It then follows that the probability of a sovereign default is given by $P($ Default $)=F\left(B_{1}\right)=F\left(B_{0}+\frac{T\left(\mathcal{S}, q_{1}\right)}{q_{1}}\right)$. Because the cumulative distribution function is increasing, it follows immediately that the default probability increases with the required bailout expenditures, but decreases with respect to the bond price $q_{1}$. In words, a higher bond price in period $t=1$ will make a sovereign default less likely. At the same time, however, the bond price depends on the government's default probability in the following way: The marginal buyers of sovereign bonds are investors who discount future cash flows at the risk-free gross interest rate $R \geq 1$. Because we assume that these investors are risk-neutral and have deep pockets, the market-clearing sovereign debt price is given by

$$
q_{1}=\frac{1-P(\text { Default })}{R}=\frac{1-F\left(B_{0}+\frac{T\left(\mathcal{S}, q_{1}\right)}{q_{1}}\right)}{R} .
$$

At this price $q_{1}$ risk-neutral investors are indifferent between buying the bond with expected payoff $1-P($ Default $)$ and the risk-free asset that guarantees the return $R$.

Equation (5) is a nonlinear equation which, in general, admits multiple solutions. As a result, there may exist multiple equilibrium sovereign debt prices, just like in the canonical models

\footnotetext{
${ }^{9}$ One interpretation would be that the government can raise any revenue it desires, but only at a stochastic cost. In this alternative scenario the government would optimally default whenever the realization of this cost exceeds some threshold.

${ }^{10}$ This assumption buys us tractability and leads to a simple analytical expression for $q_{1}$. If one were to assume partial repayment, the numerator in equation (5) would also include the integral over all possible realizations of $\tilde{\tau}$ and the corresponding pro rata repayments. The economic mechanism we want to capture is qualitatively unaffected by this "all-or-nothing" assumption on tax collection.
} 

equilibria with $q_{1}<R^{-1}$. For an extensive discussion, see Online Appendix OA.A.1

What remains to be defined is the initial sovereign debt price $q_{0}$. We assume that market

\footnotetext{
${ }^{11}$ This normalization is without loss of generality. When the government considers a bailout, it is concerned with the implied change in its default probability, not with the level.

${ }^{12}$ Note that if a monetary authority were to lower the risk-free rate $R$ it would stabilize bond prices and thus help to mitigate the impact of the doom loop. Alternative tools include outright bond purchases and collateral policy, whereby the central bank can extend the set of securities (e.g., to include more risky sovereign bonds) that banks can use as collateral to obtain lender-of-last-resort funding.

${ }^{13}$ Strictly speaking, a "market breakdown" equilibrium in which $q_{1}=0$ (the government defaults with certainty) always exists for $T>0$ as $\lim _{\tau \rightarrow \infty} F(\tau)=1$ because $F(\cdot)$ is a CDF. In our analysis we deliberately ignore this extreme coordination failure.
} 
participants at $t=0$ cannot anticipate the government's bailout choice (even after the negative shock hits bank assets), so it is not reflected in the $t=0$ bond price given by

$$
q_{0}=\frac{1-F\left(B_{0}\right)}{R}=\frac{1}{R}
$$

As a consequence, whenever $T\left(\mathcal{S}, q_{1}\right)>0$, we have $q_{1}<q_{0}$, i.e., the sovereign spread jumps up at $t=1$. In contrast, whenever $T\left(\mathcal{S}, q_{1}\right)=0$, we have $q_{1}=q_{0}=1 / R^{14}$

We are now in a position to formally state the government's problem: The government chooses the optimal subset of surviving banks to solve

$$
\begin{array}{ll}
\max _{\mathcal{S} \subseteq N} & \left.w(\mathcal{S})=-\left[\beta \sum_{i \in \mathcal{S}^{c}}\left(L^{i}+d^{i}-c^{i}-q_{1} b^{i}-\sum_{j=1}^{n} \pi^{i j} \bar{p}^{j}(\mathcal{S})\right)+\gamma B_{1} P \text { (Default }\right)\right] \\
\text { s.t. } & q_{1}=\frac{1-F\left(B_{0}+\frac{T\left(\mathcal{S}, q_{1}\right)}{q_{1}}\right)}{R} \\
& T\left(\mathcal{S}, q_{1}\right)=\sum_{i \in \mathcal{S}}\left(L^{i}+d^{i}-c^{i}-q_{1} b^{i}-(\Pi \bar{p}(\mathcal{S}))^{i}\right)^{+},
\end{array}
$$
(FDIC) required insured banks to prepay three years worth of deposit insurance premiums in

\footnotetext{
${ }^{14}$ Acharya et al. (2014) showed that bank bailouts triggered the doom loop. This result motivates our assumption that the initial shock and the government's bailout response are unanticipated events.
} 
order to replenish its depleted reserves ${ }^{15}$ By recouping used funds from within the banking industry, deposit insurance schemes aim to avoid taxpayer bailouts "through the backdoor".

\section{Equilibrium Bailout Transfers and the Doom Loop}

We begin with an observation about the sovereign debt price $q_{1}$. As explained in Online Appendix OA.A, it is decreasing in the amount of bailout expenditures, i.e., a higher price $q_{1}$ can only be achieved through lower bailout expenditures and vice versa.

Lemma 1. The equilibrium price of sovereign debt $q_{1}$ is decreasing in equilibrium aggregate bailout transfers $T\left(\mathcal{S}, q_{1}\right)$.

Using Lemma 1, we next analyze the bailout decisions in the presence of a doom loop. In Section 4.1, we focus on complete bailouts, i.e., we restrict the government's choice to either $N$ (all banks are bailed out, so $\bar{p}=L$ ) or $\mathcal{D}(\bar{p})^{c}$ (no bailout). In Section 4.2, we extend the analysis to the more general case where the government can optimally choose the set of surviving banks. All proofs of technical results are relegated to Online Appendix OA.C.

\subsection{The Doom Loop with Complete Bailouts}

To analyze how the sovereign debt distribution affects the strength of the doom loop and thus the government's bailout decision, it is helpful to first define the bailout space, i.e., the set of initial shocks for which the government prefers a complete bailout to inaction in equilibrium. Since we model the adverse shock as a reduction of banks' "cash assets", everything else equal, a larger initial shock corresponds to a (componentwise) weakly smaller vector $c$. We can therefore define the bailout space as a subset of the space of vectors $c$ (i.e., "cash" assets) for a given network structure and parameters.

Definition 2. For given $(L, \Pi, b, d)$, bankruptcy cost parameter $\beta$, risk-free interest rate $R$, and fiscal parameters $\left(B_{0}, \alpha, \gamma\right)$, the bailout space is defined as

$$
\Psi \equiv\left\{c \in \mathbb{R}^{n}: w^{B}>w^{N B}\right\}
$$

\footnotetext{
${ }^{15}$ See https://www.fdic.gov/news/press-releases/2009/pr09212.html.
} 
with $w^{B}=w(N)$ and $w^{N B}=w\left(\mathcal{D}(\bar{p})^{c}\right)$.

For comparative statics results regarding the bailout space, please see Online Appendix OA.B.

Our main research question is how the interbank network topology and the distribution of sovereign debt jointly affect the government's bailout choice. In the context of complete bailouts, answering this question boils down to evaluating the relative effects of sovereign debt distribution and network structure on $w^{B}$ and $w^{N B}$.

First note that in the case of complete bailouts all interbank liabilities are paid in full, so the network structure only matters for $w^{N B}$, as the required bailout that determines $w^{B}$ is independent of the network structure. In contrast, the presence and distribution of sovereign debt only affects $w^{B}$ as without a bailout there is no doom loop and we have $q_{1}=1 / R$ in equilibrium. Specifically, what matters for $w^{B}$ is (a) how much debt the banking sector holds, and (b) which banks hold the debt. We address both points in the following two propositions.

Proposition 1 (Sovereign exposure and the bailout space). For an identical initial level of public debt $B_{0}$, let $(L, \Pi, \tilde{c}, d, \tilde{b})$ and $(L, \Pi, \hat{c}, d, \hat{b})$ be two financial systems such that

\section{1. $\hat{b}^{i} \geq \tilde{b}^{i} \quad \forall i \in N$ with at least one inequality strict}

2. $\hat{c}^{i}=\tilde{c}^{i}-\left(\hat{b}^{i}-\tilde{b}^{i}\right) / R>0$.

Then with complete bailouts $\hat{w}^{B} \leq \tilde{w}^{B}$ and $\hat{\Psi} \subseteq \tilde{\Psi}$.

Conditions 1 and 2 in the Proposition ensure that if we move from the tilde-system to the hat-system, every bank that now holds more sovereign debt holds less cash, so that the overall initial equity or shortfall positions remain unchanged $\left(\hat{\chi}_{0}=\tilde{\chi}_{0}\right)$. In other words, these banks only differ in their asset composition across the two scenarios, but not in their total asset size or leverage. The idea of the proposition is that increasing the amount of domestic sovereign debt held by banks amplifies the feedback loop between a falling debt price $q_{1}$ and even higher transfers $T\left(N, q_{1}\right)$. Therefore, complete bailouts become more costly and as a result $\Psi$ becomes smaller. Note however that $\hat{w}^{B}$ is only weakly smaller than $\tilde{w}^{B}$, because it is possible that the banks with increased sovereign exposure are well capitalized and do not require a bailout in the first place. In that case, even though their shareholders suffer higher book value losses than in the tilde-system, these do not translate into defaults and hence do not affect the bailout space. 
Clearly, if the banks with sovereign exposure are well capitalized, they can absorb a drop in $q_{1}$ better than poorly capitalized banks. This higher loss-absorbing capacity mitigates the "doom loop"-related cost of a bailout because fewer banks need to be bailed out (see equation (3)). Even if bailing out the fundamentally defaulting banks makes additional bailouts necessary (i.e. $t^{i}\left(N, q_{1}\right)>0$ for some $i \notin \mathcal{F}$ due to $q_{1} \downarrow$ ), this bailout will still be less costly than if the sovereign debt was held entirely by the $\mathcal{F}$-banks. We present an example to illustrate the economic forces at play.

Example 1. Let $\mathcal{B} \equiv\left\{i: b^{i}>0\right\}$ denote the set of banks that hold sovereign debt and consider the following scenario: Suppose there is only one fundamentally defaulting bank $i$, and all sovereign debt in the banking sector is held by a bank $j \neq i$, so $\mathcal{F}$ and $\mathcal{B}$ would be disjoint singletons. Suppose further that the government chooses to bail out bank $i$, thereby causing a drop in the bond price that would render bank $j$ insolvent. Then, according to our definition of complete bailouts, the government also has to transfer bailout funds to bank $j \in \mathcal{B}$. However, as long as bank $j$ initially had a positive equity buffer, the total required bailout $\left(t^{i}+t^{j}\right)$ will be smaller than if only bank $i$ had held the sovereign debt stock (i.e. if $\mathcal{F}=\mathcal{B}=\{i\}$ ) and the doom loop had hit bank $i$ without any capital buffer mitigation.

The insight from this stylized example carries over to more dispersed distributions of sovereign debt among banks. We formally state this intuitive result in the following proposition:

Proposition 2 (Sovereign exposure and capital buffers). Let $(L, \Pi, \tilde{c}, d, \tilde{b})$ and $(L, \Pi, \hat{c}, d, \hat{b})$ be two financial systems such that

1. $\hat{b}^{i}<\tilde{b}^{i} \forall i: V_{0}^{i}<\tilde{b}^{i}\left(R^{-1}-\tilde{q}_{1}^{\max }\right)$

2. $\sum_{i \in N} \hat{b}^{i}=\sum_{i \in N} \tilde{b}^{i}$

3. $\hat{c}^{i}=\tilde{c}^{i}-\left(\hat{b}^{i}-\tilde{b}^{i}\right) / R>0$,

where $\tilde{q}_{1}^{\text {max }}$ is the unique positive solution of $R \tilde{q}_{1}^{\max }=1-F\left(\frac{\sum_{i \in \mathcal{F}} \chi_{0}^{i}}{\tilde{q}_{1}^{\max }}\right)$. Then with complete bailouts $\hat{w}^{B}>\tilde{w}^{B}$ and $\hat{\Psi} \supset \tilde{\Psi}$.

The two financial systems described in the proposition only differ in the distribution of domestic sovereign debt, with aggregate sovereign exposure in the banking system and initial 
shortfalls held constant (conditions 1 and 3 imply $\hat{\chi}_{0}=\tilde{\chi}_{0} \equiv \chi_{0}$ ). More precisely, the banks with capital buffers $V_{0}^{i}$ below an exogenous threshold hold less sovereign debt in the hat-system than in the tilde-system (condition 1), which requires that banks with $V_{0}^{i}$ above the threshold hold more $\sqrt{16}$ Then, the proposition states that redistributing domestic sovereign debt from

\footnotetext{
${ }^{16}$ This threshold depends on $\tilde{q}_{1}^{\max }$, i.e., the upper bound on the bond price in case of a bailout. This is the price that would prevail if only the initial shortfall had to be covered because none of the banks in $\mathcal{F}$ held any sovereign debt. Hence, the banks referred to in condition 1 are those whose capital buffers could not even absorb the lowest possible drop in the sovereign bond price.

${ }^{17}$ See https://www.fdic.gov/resources/resolutions/bank-failures/failed-bank-list/ffor details.
} 
In Europe, severe banking crises in Iceland and Cyprus even saw (mostly foreign) depositors lose large shares of their investments. Moreover, the failure of the Spanish Banco Popular in 2017 was the first litmus test of the new bail-in regime with significant creditor participation.

370

\footnotetext{
${ }^{18}$ It is, however, possible to solve (8) numerically. For details about the algorithm we use, see Online Appendix OA.E.
} is generally difficult to make analytical statements about the optimal set of surviving banks $\mathcal{S}^{*}$.18 Therefore, to develop a better understanding of the economic forces that determine the government's bailout decision, from now on we ignore the "global" solution of (8) and focus instead on "local" analysis in the following sense: Suppose that instead of choosing the optimal subset among all feasible subsets of surviving banks, the government could only bail out one bank at a time. Starting from the laissez faire outcome with defaulting banks $\mathcal{D}(\bar{p})$, the government computes for every troubled bank the net welfare gain that would result from bailing it out. As long as a welfare improvement is possible in this way, the government adds the bank with the highest net welfare gain to the set of surviving banks. The procedure stops once there is no troubled bank left that can be bailed out without increasing welfare losses.

There is no guarantee that the set thus constructed coincides with the "globally" optimal set $\mathcal{S}^{*}$ which solves (8). However, the fictional sequential procedure allows us to at least analyze "local" optima, i.e., we can pin down bank-specific properties that determine which bank will be bailed out at any given step of the procedure. In this way, even though it is impossible to characterize the global solution of the optimal bailout problem analytically, we can make valid statements about incremental improvements. What is more, the sequential procedure allows 

surviving banks $\mathcal{S}$, by bailing out bank $i \in \mathcal{S}^{c}$ the government avoids bankruptcy deadweight losses of

$$
\begin{aligned}
& \beta \sum_{j \in \mathcal{I}}\left[\chi_{1}^{j}+\left(L^{j}-\bar{p}^{j}(\mathcal{S})\right) \times\right. \\
& \left.\left(\sum_{k} \pi^{k j}+(1+\beta) \sum_{k} \sum_{l} \pi^{l k} \pi^{k j}+(1+\beta)^{2} \sum_{k} \sum_{l} \sum_{m} \pi^{m l} \pi^{l k} \pi^{k j}+\ldots\right)\right],
\end{aligned}
$$

where $\mathcal{I}$ denotes the set of banks that become solvent through the bailout (with $i \in \mathcal{I}$ ) and all summations except the first are over the remaining default set $\mathcal{S}^{c} \backslash \mathcal{I}$. The expression in (10) captures (a) the direct impact of avoiding bankruptcy deadweight losses $\beta \chi_{1}^{j}$ for banks in $\mathcal{I}$, and (b) the indirect impact of their increased interbank repayments. The idea is that the increase in repayments from $\bar{p}^{j}(\mathcal{S})$ to $L^{j}$ not only increases $j$ 's creditors' assets available for repayment, but also reduces their shortfall and hence their deadweight losses. For example, if 
bank $j$ fully repays, its creditor $k$ 's shortfall decreases by $\pi^{k j}\left(L^{j}-\bar{p}^{j}(\mathcal{S})\right)$ and its repayment $\bar{p}^{k}$ even increases by $(1+\beta) \pi^{k j}\left(L^{j}-\bar{p}^{j}(\mathcal{S})\right)$, and so on. In other words, the positive effect of the bailout travels through the subnetwork of defaulting banks and is amplified by the bankruptcy cost coefficient $\beta$ at each node.

The expression in $(10)$ can be further simplified. Observe that the increase in interbank repayments is bounded from above by $L^{j}$, namely if bank $j$ originally could not even partially repay its interbank liabilities $\left(\bar{p}^{j}(\mathcal{S})=0\right)$. Otherwise, that is if $\bar{p}^{j}(\mathcal{S})>0 \forall j \in \mathcal{I}: L^{j}>0$, we can use Definition 1 to show that $L^{j}-\bar{p}^{j}(\mathcal{S})=(1+\beta) \chi_{1}^{j}$. For ease of notation we restrict our subsequent analysis to the latter case, so that the expression in $(10)$ becomes

$$
\beta \sum_{j \in \mathcal{I}} \chi_{1}^{j} \underbrace{\left(1+(1+\beta) \sum_{k} \pi^{k j}+(1+\beta)^{2} \sum_{k} \sum_{l} \pi^{l k} \pi^{k j}+\ldots\right)}_{C^{j}}
$$

We remark, however, that our results would qualitatively hold in the general case where depositors receive payments through deposit insurance, i.e., if there exists some bank $j$ with positive interbank liabilities $L^{j}>0$ which makes zero payments to its creditors in the network.

Borrowing from Glasserman and Young (2015), we refer to the term in parentheses as the "node depth" of bank $j$ and denote it by $C^{j}$ which stands for "centrality". Node depth measures the extent to which any loss originating at bank $j$ gets spread and amplified in the subnetwork of defaulting banks. Therefore, it is naturally increasing in the set of defaulting banks, i.e., for a given network $\Pi$, node depth of any individual bank is weakly higher if more banks default. Let $\mathcal{D}$ be a set of defaulting nodes, and $\Pi_{\mathcal{D}}$ be the $|\mathcal{D}| \times|\mathcal{D}|$ matrix obtained by restricting the relative liabilities matrix $\Pi$ to $\mathcal{D}$. Moreover, denote by $I_{\mathcal{D}}$ be the $|\mathcal{D}| \times|\mathcal{D}|$ identity matrix, and let $\Pi_{\mathcal{D}}^{\prime}$ denote the transpose of matrix $\Pi_{\mathcal{D}}$. Then, the vector of node depths of banks in $\mathcal{D}$ is given by $\left[I_{\mathcal{D}}-(1+\beta) \Pi_{\mathcal{D}}^{\prime}\right]^{-1} \cdot \mathbb{1}_{\mathcal{D}}$ if the spectral radius of $(1+\beta) \Pi_{\mathcal{D}}^{\prime}$ is less than one.

This technical condition has a clear economic interpretation: For node depth to be well defined, if there are cycles in the subnetwork of defaulting banks (i.e., if there exists a sequence 435 $\left(\pi^{i_{1} i_{2}}, \pi^{i_{2} i_{3}}, \ldots, \pi^{i_{k} i_{1}}\right), i_{m} \in \mathcal{D}$ and $m=1, \ldots, k$, whose entries are all non-zero), the entries of the relative liability matrix $\Pi_{\mathcal{D}}$ have to be sufficiently small. In other words, in case of cycles the defaulting banks need to owe a sufficient fraction of their liabilities to solvent banks outside 
of $\mathcal{D}$. The higher the bankruptcy cost parameter $\beta$, the lower the relative exposures within the defaulting set must be, otherwise there would be too much amplification of welfare losses

\footnotetext{
${ }^{19}$ In Online Appendix OA.D, we derive exact conditions on model primitives which guarantee a spectral radius smaller than unity for default sets of size two and three.
} 
even for identical shortfalls, bailing out banks with more sovereign debt on their balance sheets comes with a higher $\gamma$-component than bailing out low-exposure banks. We refer to Online Appendix OA.C for a formal proof of this "doom loop multiplier" property. Third, depending on the sovereign exposure of banks in $\mathcal{S}$, it may happen that the drop in $q_{1}$ makes additional bailout transfers to other banks necessary to prevent their insolvency. The cost of raising these funds will also be reflected in the $\gamma$-component. Fourth and finally, it matters whether or not bank $i$ is part of a cycle in the subnetwork of defaulting banks $\mathcal{S}^{c}$. If so, then bailing out $i$ eventually also increases the interbank repayments it receives, thereby reducing the effective shortfall the government needs to cover according to (3). Summing up, to minimize the $\gamma$ component of the bailout cost, the government would ideally bail out banks that have only a low shortfall to begin with, hold little sovereign debt, and have interbank claims on other defaulting banks that have themselves (direct or indirect) claims on the bailout candidate.

To complete the picture, we turn to the $\beta$-component which describes the additional default deadweight losses that are triggered by the drop in the price of the sovereign bond, which we denote by $\Delta^{i} q_{1}<0$. The bailout of bank $i$ causes deadweight losses in the amount of $\left|\beta \Delta^{i} q_{1} b^{j}\right|$ for each defaulting bank $j \in \mathcal{S}^{c} \backslash \mathcal{I}$ which will then be amplified in proportion to their centrality $C^{j}$. This means that the side effects of a bailout can become very costly if the remaining defaulters are highly exposed to their government and very central in the subnetwork of defaulting banks. It is exactly this key observation that will give rise to our main result further below.

Lemma 2 (Decomposition of net welfare effect). For a given initial set of surviving banks $\mathcal{S}$, the net welfare effect $\Delta^{i} w$ of bailing out bank $i \in \mathcal{S}^{c}$ can be written as

$$
\Delta^{i} w=\underbrace{\beta \sum_{j \in \mathcal{I}} \chi_{1}^{j} \times C^{j}}_{\text {Benefit }} \underbrace{+\beta \sum_{j \in \mathcal{S}^{c} \backslash \mathcal{I}} \Delta^{i} q_{1} b^{j} \times C^{j} \underbrace{-\gamma \Delta^{i}\left(B_{1} P(\text { Default })\right)}_{\gamma \text {-component }}}_{\text {Cost }},
$$

where $\Delta^{i} q_{1}<0$ and $\Delta^{i}\left(B_{1} P(\right.$ Default $\left.)\right)>0$ denote changes implied by the bailout of $i$.

The lemma allows us to make a number of statements about which banks deliver the highest welfare improvements if bailed out. For example, note that in an economy without bank-held 
domestic sovereign debt $(b=0)$, the $\beta$-component would disappear and banks could be ranked

1. $\tilde{b}=0$

2. $\hat{b}^{k}=b^{\prime}>0 \forall k \in N$

3. $\hat{c}=\tilde{c}-\hat{b} / R$ (which implies $\left.\hat{\chi}_{1}=\tilde{\chi}_{1} \equiv \chi_{1}\right)$.

\footnotetext{
${ }^{20}$ This insight echos a number of results from a more general literature about intervention in networks. For instance, Galeotti et al. (2020) show that in network games of strategic complements, the optimal intervention allocated to a given node is proportional to its eigenvector centrality.
} 
Moreover, let $i, j \in \mathcal{S}^{c}$ be two banks that differ only in their node depth, with $C^{i}>C^{j}$. In particular, they have identical shortfalls $\chi_{1}^{i}=\chi_{1}^{j}$ and cause the same set of contagious defaults $\mathcal{I} \backslash i=\mathcal{J} \backslash j$. Then we have

$$
\tilde{\Delta}^{i} w>\tilde{\Delta}^{j} w, \quad \hat{\Delta}^{i} w>\hat{\Delta}^{j} w, \quad \text { and } \quad \hat{\Delta}^{i} w-\hat{\Delta}^{j} w>\tilde{\Delta}^{i} w-\tilde{\Delta}^{j} w
$$

Therefore, whether a given bank $i \in \mathcal{B}$ will optimally be bailed out depends on the relative strength of these two forces. Crucially, whereas the first effect applies to each bank equally, the 
second effect is proportional to a bank's network centrality. In particular, a bank with high centrality and sovereign exposure is more likely to be bailed out than an identical bank with little or no exposure. In contrast, peripheral banks (for which the second effect is negligible) are unambiguously less likely to be saved the more sovereign bonds they hold. We formalize this main result in the following proposition.

Proposition 4 (Sovereign debt distribution within networks). Let $i, j \in \mathcal{S}^{c}$ be two banks that differ only in their asset composition $\left(b^{i}>b^{j}\right.$ and $\left.c^{i}<c^{j}\right)$. In particular, they have identical shortfalls $\chi_{1}^{i}=\chi_{1}^{j} \equiv \chi_{1}$ and centrality $C^{i}=C^{j} \equiv C$ and cause the same set of contagious defaults $\mathcal{I} \backslash i=\mathcal{J} \backslash j$. Then $\exists C^{*}$ such that

$$
\Delta^{i} w>\Delta^{j} w \quad \text { iff } \quad C \geq C^{*}
$$

as long as $\frac{b^{i}}{b^{j}}>\frac{\Delta^{i} q_{1}}{\Delta^{j} q_{1}}>1$. The threshold $C^{*}$ is increasing in $\gamma$ and decreasing in $\beta$.

If the government has to choose between two otherwise identical banks, whether it will pick the one with more or less domestic sovereign exposure depends on the banks' centrality $C$. The reason is that the welfare losses due to the $\beta$-component (which are higher if bank $j$ with the smaller sovereign exposure is saved) are proportional to centrality $C$, as shown in Lemma 2. Hence, for large $C$ (e.g., if the interbank network is highly interconnected) the difference in $\beta$-components dominates the difference in the $\gamma$-components so that bailing out bank $i$ becomes more attractive. In contrast, in less interconnected systems (low $C$ ) the $\beta$-component carries only little weight in the welfare comparison and the lower $\gamma$-component leads the government to bail out bank $j$.

Finally, note that our proposition requires that the difference in sovereign exposures must overcompensate the difference in absolute price changes, i.e. $b^{i}$ and $b^{j}$ must be sufficiently different. Otherwise the fact that saving bank $i$ has a stronger price impact $\left(\left|\Delta q_{1}^{i}\right|>\left|\Delta q_{1}^{j}\right|\right)$ dominates the $\beta$-component so that the government unambiguously prefers to save bank $j$, regardless of centrality.

We illustrate the result through a stylized numerical example with $n=4$ banks: Suppose 560 the government initially owes a debt stock of $B_{0}=120$ (which may be interpreted as $120 \%$ of GDP), of which $20 \%$ is held by the domestic banking sector, so $\sum_{i \in N} b^{i}=24$. The gross risk-free 
interest rate is $R=1.02$, hence the initial sovereign bond price is given by $q_{0}=R^{-1}=0.9804$. Moreover, we pick the shape parameter of the (Pareto) tax capacity distribution to be $\alpha=0.9$ which delivers quantitatively reasonable movements in sovereign spreads.

Table 1 summarizes banks' initial balance sheets (i.e. before the unanticipated fundamental shock happens). Total balance sheet size is chosen such that the average bank holds $10 \%$ of its balance sheet in domestic sovereign debt, similar to Italy in Figure 1. To maintain transparency and simplicity, we initially let every bank have the same balance sheet size and leverage (equity buffer $=10 \%$ of total assets). Note, however, that banks 1 and 3 each hold twice as much sovereign debt as the remaining banks. The interbank network is visualized in Figure 3 .

[Figure 3 about here.]

Banks 1 and 2 have no interbank liabilities, but are lending to banks 3 and 4. All four banks' "cash" assets are reduced by the shock such that their total assets drop by $20 \%$, leaving them with a shortfall of $10 \%$ each. Summing up, this is the simplest possible setup to demonstrate the content of the proposition; we have two sets of almost identical failing banks (1 vs. 2 and 3 vs. 4) that only differ in terms of sovereign exposure within pairs. In particular, banks 1 and 2 have a trivial node depth of $C^{1}=C^{2}=1$ (because they do not have any interbank liabilities) whereas banks 3 and 4 have $C^{3}=C^{4}=2.8$. Just like the proposition states, among the peripheral banks the government prefers bailing out the low- $b$ bank $2\left(\Delta^{2} w=-4.16\right)$ to the high- $b$ bank $1\left(\Delta^{1} w=-4.39\right)$, but among the more central banks it prefers the high- $b$ bank $3\left(\Delta^{3} w=8.07\right)$ to the low-b bank $4\left(\Delta^{4} w=7.83\right)$.

One interpretation of the result in Proposition 4 is that the doom loop alters the government's ranking of banks to be rescued. Whereas in a world without the doom loop (e.g., with $b=0$ ), the government would be indifferent between two banks with the same shortfall $\chi_{1}$ and node depth $C$, the different exposures to the doom loop now break the tie. In other words, network centrality alone is not sufficient anymore to pin down the optimal set of bailedout banks. This highlights the doom loop as a new channel of contagion that conventional centrality measures cannot capture. 
Another way of looking at the effect of holding more domestic sovereign debt is across networks (whereas Proposition 4 is based on a within-network comparison). To this end we consider two financial systems that are identical in every regard, except that an arbitrary defaulting bank $i$ holds more sovereign debt in one system that in the other (conditions 1 and 2 below). To keep the overall surplus of the system unchanged, suppose that this bank holds less cash so that its overall shortfall remains unchanged (condition 3). The following proposition shows that whether the higher $b^{i}$ in the second system increases or decreases bank $i$ 's position in the government's "bailout ranking" depends on its centrality.

Proposition 5 (Sovereign debt distribution across networks). For a fixed $B_{0}$, let $(L, \Pi, \tilde{c}, d, \tilde{b})$ and $(L, \Pi, \hat{c}, d, \hat{b})$ be two financial systems such that

1. $\exists ! i \in \mathcal{S}^{c}: \hat{b}^{i}>\tilde{b}^{i}$

2. $\hat{b}^{j}=\tilde{b}^{j}$ and $\hat{c}^{j}=\tilde{c}^{j} \forall j \neq i$

3. $\hat{c}^{i}=\tilde{c}^{i}-\left(\hat{b}^{i}-\tilde{b}^{i}\right) / R$.

Then $\forall j \neq i \exists C^{*}(j)$ such that

$$
\hat{\Delta}^{i} w-\hat{\Delta}^{j} w>\tilde{\Delta}^{i} w-\tilde{\Delta}^{j} w \quad \text { iff } \quad C^{i} \geq C^{*}(j)
$$

The threshold is increasing in $\gamma$ and decreasing in $\beta,\left|\hat{\Delta}^{j} q_{1}\right|$ and $\left(\hat{b}^{i}-\tilde{b}^{i}\right)$.

The above proposition can be easily explained thanks to the decomposition in Lemma 2 . The benefit component is the same in both networks. On the cost side, in the hat-network bailing out bank $i$ results in a larger $\beta$-component and a larger $\gamma$-component than in the tildenetwork because of the doom loop multiplier and the corresponding larger price impact. As a consequence, the absolute net benefit of bailing out $i$ is clearly lower in the hat-network, i.e. $\hat{\Delta}^{i} w<\tilde{\Delta}^{i} w$. However, all other bailout candidates $j$ also see their $\beta$-component increase (and thus their $\Delta^{j} w$ fall) because the defaulting $i$ now holds more sovereign debt. Moreover, this increase in the $\beta$-component is an increasing function of $i$ 's centrality. Hence, if $i$ is central enough it can even end up higher in the government's ranking than before.

Using again our above numerical example, suppose we double low-C bank 2's sovereign bond holdings from 4 to 8 . Then, the net welfare effect of bailing out bank 2 changes to $\Delta^{2} w=$ 
${ }_{615}-6.38<-5.76=\Delta^{1} w$, thus bank 2 drops even below bank 1 in the government's ranking. In contrast, if we double high-C bank 4's bond holdings, we get $\Delta^{4} w=7.26>6.81=\Delta^{3} w$, then bank 4 becomes first in the ranking.

Summing up, our results show that a higher $b^{i}$ does not make a bailout of $i$ more attractive in absolute terms, nor does it increase the government's propensity to engage in a bailout in the first place. However, it can make bailing out other banks even less attractive, namely if $i$ is sufficiently central in the interbank network.

\subsection{Testable Implications and Empirical Examples}

Even though banks are not strategic in our framework, the results outlined in the previous section have important implications for banks' portfolio choice ex ante. We have shown that, 625 depending on a bank's centrality, higher sovereign exposure can make a bailout of that bank more likely ex post. Hence, if banks value the prospect of a bailout and anticipate the government's best response, they can use their sovereign debt portfolio to affect the odds of being bailed out. One way to illustrate this is the following: Suppose that at $t=-1$ banks learn their position in the interbank network (and hence their node depth for each shock realization) and can choose their domestic sovereign exposure. Then, banks with high centrality can increase the chance to be bailed out by purchasing more sovereign debt than otherwise identical banks.

More generally, our model generates a number of testable hypotheses, though actually testing the model is challenging, both because of a lack of data and the complexity of the interactions we have identified. Nevertheless, we have identified a few key parameters and variables 635 to which attention should be directed. Accordingly, the following remarks should be viewed as speculative, but they suggest the power of the lens on financial markets that our paper brings to bear.

If banks understand and exploit the logic in our analysis, we should, for instance, observe a positive correlation between banks' node depth and their domestic sovereign bond holdings

${ }_{640}$ (at least in countries where the "doom loop" is a real threat). Moreover, we should expect the correlation to be larger in financial systems where bankruptcy costs are higher based on the fact that the centrality thresholds in Propositions 4 and 5 are decreasing in $\beta$.

Our results may help partly shed some light on historical bailout decisions, and highlight 
factors to account for in determining future bank bailouts. First, note that our results on

how network structure and sovereign bond holdings interact are only valid in case of an active "doom loop", i.e., if sovereign bond prices drop in response to a bailout. In countries with very safe public debt (e.g., the US, Germany, or Switzerland) the interaction highlighted in the previous section is absent. In other words, the amount and distribution of sovereign bonds held by domestic banks would not matter for the government's optimal bailout decision. Thus the bailout of AIG (and the indirect bailout of Goldman Sachs) in 2008 can be attributed either to their centrality in the financial system or their political influence, but not to their holdings of government bonds and the doom loop properties upon which we have focused. In contrast, Greece and Spain may evidence patterns that are more consistent with the predictions of our study.

55 Second, for countries with more efficient resolution mechanisms (low $\beta$ ), our results predict not only fewer bank bailouts altogether, but also that optimal bailouts will generally be targeted at banks with lower sovereign bond holdings that require smaller bailouts. The same conclusions hold for countries that would suffer more from a sovereign default (high $\gamma$ ). Again, Spain, Greece, as well as Cyprus and Iceland may provide data sets against which these hypotheses may be tested.

Finally, recent regulatory efforts in Europe to complete the "banking union" included attempts to make bank resolutions more efficient and thus failures less costly. In our model, this corresponds to a drop in $\beta$, which makes partial bailouts (or even "no bailout") more attractive relative to complete bailouts. Therefore, compared to the global financial crisis of 2008/09, we expect to see more partial bailouts in the future, and that would provide the ultimate test for our theoretical predictions. Apart from being ex post optimal, there would be an additional benefit in letting some banks fail: As Philippon and Wang (2021) show, a credible announcement of partial bailouts can also help to discipline banks' risk-taking behavior ex ante. But even if political pressures necessitate a bailout of all banks that might be in stress, an awareness of the interplay between the structure of the financial network and the workings of the doom loop should enable the design of regulatory policies that reduce the overall bailout cost. 


\section{Conclusion}

In this paper we study the government's optimal bailout strategy in a banking crisis if (a) financing a bailout depresses the value of domestic sovereign debt on bank balance sheets (the "doom loop") and (b) banks are connected to each other through a network of liabilities.

We find, not surprisingly, that the doom loop is weaker (and bailouts therefore less costly) if banks hold less domestic sovereign debt or if banks with large domestic sovereign exposure are well capitalized. This result is directly related to the current debate about higher regulatory capital charges for sovereign exposure in the eurozone (see Véron (2017)).

Moreover, we show that the government can rank otherwise identical banks according to their "node depth", a centrality measure introduced by Glasserman and Young (2015). Compared to a situation without sovereign debt on banks' balance sheets, even a uniform distribution of sovereign debt across banks strengthens the role of centrality as a tiebreaker and thus exacerbates the "too interconnected to fail" problem.

Our main result is that the optimal subset of banks to bail out depends jointly on their position in the interbank network and their domestic sovereign exposure. In particular, if banks with high amounts of sovereign bonds are sufficiently central, the government may prefer to save them rather than banks with low domestic sovereign exposure, even though this requires a larger bailout. Equivalently, if there is a bailout, highly central banks are more likely to be part of it if they hold more sovereign debt since that increases the cost of letting them fail. While higher sovereign exposure unambiguously makes the bailout of a given bank more expensive, it can make bailing out other banks even more costly.

As a consequence, we argue that a bank's position in the network may have strategic implications for its individually optimal domestic sovereign exposure. Systemically important banks might be able to use domestic sovereign debt as a "strategic tool" to increase the likelihood of being bailed out. Our model therefore provides a new, network-based perspective on the question of why banks in stressed European countries increased their domestic sovereign bond holdings during the European sovereign debt crisis.

Our framework may be extended along several interesting dimensions. An obvious, yet ambitious extension is to develop a fully fledged game theoretical model, in which banks take their position in the network as given and strategically choose their sovereign bond holdings 
to maximize an exogenously specified objective function. Banks would thus endogenously construct their balance sheet in anticipation of government intervention to maximize their bailout option.

Second, in our model the government has full information about banks' balance sheets, in particular their interbank exposures. In reality, uncertainty about these interlinkages poses a challenge to policymakers and can lead to second-best policy outcomes. Moreover, as in Caballero and Simsek (2013), uncertainty about the structure of the financial network can exacerbate endogenous responses such as funding withdrawals or fire sales. Ever since at least the global financial crisis, researchers have tried to uncover "true" financial networks, e.g. by estimating underlying links from aggregates. ${ }^{21}$ In recent years, however, central banks around the world have stepped up their efforts to gather the necessary data in order to monitor systemic risk. As a result, they now have access to a wealth of information not just about banks' aggregate balance sheet items, but also counterparty-level exposures in different asset classes (e.g. loans, securities, or derivatives). For instance, the ECB can construct financial networks using a large European credit register (AnaCredit), security holdings statistics (SHS), or bilateral money market trading data (MMSR). Therefore, we believe that the assumption of full information is not too far from the current reality.

Third, an alternative way to resolve banking crises (instead of public bailouts) is to encourage mergers of failing and healthy banks. Network models like the one presented in this paper offer an interesting framework to study these mergers, which can be modelled as combining two nodes (and consolidating their balance sheets). In doing so, policymakers would not only avoid bank defaults, but also alter the network structure. However, depending on the distribution of future shocks, a merger might also increase future instability by creating a new "too big/interconnected to fail" institution. The resulting tradeoff is a promising topic for future research.

Fourth, our model deliberately abstracts from the "real economy loop" in Brunnermeier et al. (2016). We do not consider the fact that bank failures could also affect the sovereign's creditworthiness without bailouts through a reduction in lending, an investment slump, and reduced tax capacity. Incorporating this channel in our model would increase the direct macroeconomic

\footnotetext{
${ }^{21}$ See, for instance, Anand et al. (2018) for a comprehensive survey of different estimation methods.
} 
Altinoglu, L., Stiglitz, J.E., 2020. Collective Moral Hazard and the Interbank Market. Working Paper. Board of Governors of the Federal Reserve System.

Anand, K., van Lelyveld, I., Banai, d., Friedrich, S., Garratt, R., Halaj, G., Fique, J., Hansen, 755 I., Jaramillo, S.M., Lee, H., Molina-Borboa, J.L., Nobili, S., Rajan, S., Salakhova, D., Silva, T.C., Silvestri, L., de Souza, S.R.S., 2018. The Missing Links: A Global Study on Uncovering Financial Network Structures from Partial Data. Journal of Financial Stability 35, 107-119.

Battiston, S., Gatti, D.D., Gallegati, M., Greenwald, B., Stiglitz, J.E., 2012a. Default Cascades: When Does Risk Diversification Increase Stability? Journal of Financial Stability 8, 138-149. 
Battiston, S., Gatti, D.D., Gallegati, M., Greenwald, B., Stiglitz, J.E., 2012b. Liaisons Dangereuses: Increasing Connectivity, Risk Sharing, and Systemic Risk. Journal of Economic Dynamics and Control 36, 1121-1141.

Baudino, P., Defina, R., Real, J.M.F., Hajra, K., Walters, R., 2019. Bank Failure Management-the Role of Deposit Insurance. FSI Insights on Policy Implementation .

Bernard, B., Capponi, A., Stiglitz, J.E., 2022. Bail-Ins and Bail-Outs: Incentives, Connectivity, and Systemic Stability. Journal of Political Economy. Forthcoming .

Brunnermeier, M., Crockett, A., Goodhart, C.A., Persaud, A., Shin, H.S., et al., 2009. The Fundamental Principles of Financial Regulation. volume 11. ICMB, Internat. Center for Monetary and Banking Studies Geneva.

Brunnermeier, M.K., Garicano, L., Lane, P.R., Pagano, M., Reis, R., Santos, T., Thesmar, D., Van Nieuwerburgh, S., Vayanos, D., 2016. Breaking the Sovereign-Bank Diabolic Loop: A Case for ESBies, in: American Economic Review Papers and Proceedings.

Caballero, R.J., Simsek, A., 2013. Fire Sales in a Model of Complexity. The Journal of Finance 68, 2549-2587.

775 Cabrales, A., Gale, D., Gottardi, P., 2016. Financial Contagion in Networks, in: Bramoulle, Y., Galeotti, A., , Rogers, B.W. (Eds.), The Oxford Handbook of the Economics of Networks. Oxford: OUP.

Cabrales, A., Gottardi, P., Vega-Redondo, F., 2017. Risk Sharing and Contagion in Networks. The Review of Financial Studies 30, 3086-3127.

Calvo, G.A., 1988. Servicing the Public Debt: The Role of Expectations. The American Economic Review , 647-661.

Cole, H.L., Kehoe, T.J., 2000. Self-fulfilling Debt Crises. The Review of Economic Studies 67, 91-116.

Cooper, R., Nikolov, K., 2018. Government Debt and Banking Fragility: The Spreading of Strategic Uncertainty. International Economic Review 59, 1905-1925.

Crosignani, M., 2021. Bank Capital, Government Bond Holdings, and Sovereign Debt Capacity. Journal of Financial Economics 141, 693-704.

Demirci, I., Huang, J., Sialm, C., 2019. Government Debt and Corporate Leverage: International Evidence. Journal of Financial Economics 133, 337-356.

Eisenberg, L., Noe, T.H., 2001. Systemic Risk in Financial Systems. Management Science 47, 236-249.

Elliott, M., Golub, B., Jackson, M.O., 2014. Financial Networks and Contagion. The American Economic Review 104, 3115-3153.

Erol, S., 2019. Network Hazard and Bailouts Mimeo. 
Kiyotaki, N., Moore, J., 1997. Credit Chains Mimeo.

Philippon, T., Wang, O., 2021. Let the Worst One Fail: A Credible Solution to the Too-BigTo-Fail Conundrum. Working Paper 29560. National Bureau of Economic Research.

Popov, A., Van Horen, N., 2015. Exporting Sovereign Stress: Evidence from Syndicated Bank

Shleifer, A., Vishny, R., 2011. Fire sales in finance and macroeconomics. Journal of Economic Perspectives 25, 29-48.

Upper, C., 2011. Simulation methods to assess the danger of contagion in interbank markets. Journal of Financial Stability 7, 111-125.

Véron, N., 2017. Sovereign Concentration Charges: A New Regime for Banks' Sovereign Exposures, in: Study for the European Parliament, Brussels. IDEAS FROM THE 'FUTURE EUROPE' FORUM. 


\section{List of Figures}

$1 \quad$ Banks' domestic sovereign exposure (as a share of total bank assets) . . . . . . . 36

825

2 A solvent bank $i$ 's balance sheet at $\mathrm{t}=0$. . . . . . . . . . . . . 37

3 Banks 3 and 4 each borrow from banks 1 and $2 \ldots \ldots$ 


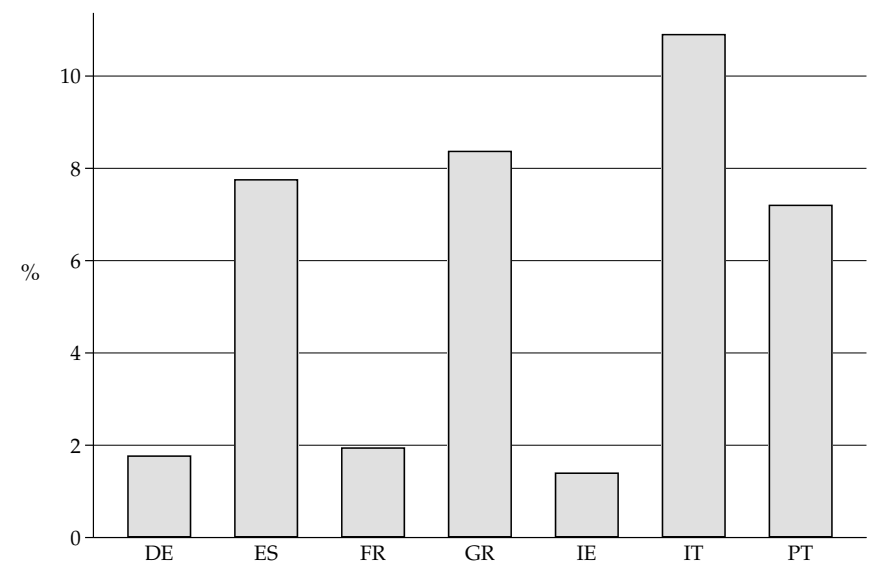

Source: ECB Statistical Data Warehouse (March 2021)

Figure 1: Banks' domestic sovereign exposure (as a share of total bank assets) 


\begin{tabular}{c|c} 
Assets & Liabilities \\
\hline$c^{i}$ & $d^{i}$ \\
\hline$(\Pi L)^{i}$ & $L^{i}$ \\
$q_{0} b^{i}$ & $V_{0}^{i}$ \\
\hline &
\end{tabular}

Figure 2: A solvent bank $i$ 's balance sheet at $\mathrm{t}=0$ 
Figure 3: Banks 3 and 4 each borrow from banks 1 and 2

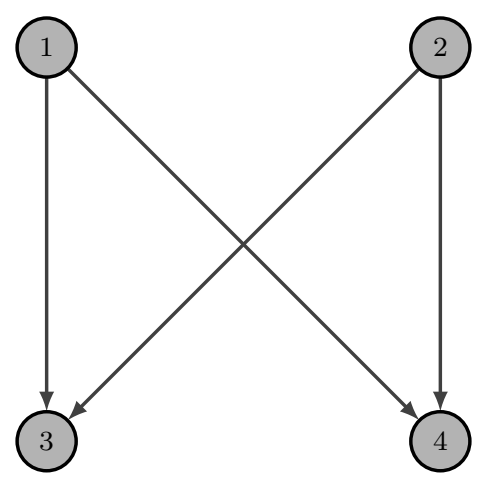




\section{List of Tables}

1 Balance sheet structure of banks in the network . . . . . . . . . . . . . . . . . . 40 
Table 1: Balance sheet structure of banks in the network

\begin{tabular}{lcccc} 
& 1 & 2 & 3 & 4 \\
\hline$c^{i}$ & 27.5 & 31.4 & 51.0 & 54.9 \\
$b^{i}$ & 8.0 & 4.0 & 8.0 & 4.0 \\
$(\pi L)^{i}$ & 23.5 & 23.5 & 0 & 0 \\
\hline Total assets & 58.8 & 58.8 & 58.8 & 58.8 \\
\hline$d^{i}$ & 52.9 & 52.9 & 29.4 & 29.4 \\
$L^{i}$ & 0 & 0 & 23.5 & 23.5 \\
\hline Total liabilities & 52.9 & 52.9 & 52.9 & 52.9 \\
\hline Equity & 5.88 & 5.88 & 5.88 & 5.88 \\
\hline$C^{i}$ & 1 & 1 & 2.8 & 2.8 \\
\hline$\Delta^{i} w$ & -4.39 & -4.16 & 8.07 & 7.83 \\
\hline
\end{tabular}

Note: Banks 1 and 3 hold more sovereign debt than 2 and 4, respectively. 